\title{
Vitamin D metabolites in idiopathic infantile hypercalcaemia
}

\author{
N D T MARTIN, G J A I SNODGRASS, R D COHEN, C E PORTEOUS, R D COLDWELL, \\ D J H TRAFFORD, AND H L J MAKIN
}

Departments of Child Health and Chemical Pathology, and Medical Unit, London Hospital Medical College

SUMMARY Metabolites of vitamin D were measured in plasma from 83 patients with idiopathic infantile hypercalcaemia syndrome who were mentally handicapped but had normal calcium values at the time of the study. No significant difference was detected in the mean plasma concentrations of 25-hydroxyvitamin D2, 1,25-dihydroxyvitamin D, 24,25-dihydroxyvitamin D3, or 25,26-dihydroxyvitamin D3 between patients and age matched controls. The mean plasma concentration of 25-hydroxyvitamin D3 was significantly lower in patients than controls but this may be a secondary phenomenon related to less sunlight exposure. In addition, two hypercalcaemic patients with this syndrome were studied during the first year of life, and were found to have normal concentrations of vitamin D metabolites. These findings do not support a role for abnormal vitamin $\mathrm{D}$ metabolism in the pathogenesis of this syndrome.

Idiopathic infantile hypercalcaemia may be associated with a congenital dysmorphic syndrome which is characterised by the elfin facies, supravalvular aortic or pulmonary stenosis, mental handicap, and dental abnormalities. ${ }^{1-3}$ We have recently reviewed 117 patients with this dysmorphic syndrome, 76 of whom had documented evidence of hypercalcaemia during infancy, highlighting some of the clinical features. ${ }^{4}$

The cause of this syndrome is unknown but Lightwood ${ }^{5}$ was the first to suggest that an abnormality of vitamin D metabolism might cause the hypercalcaemia. Calcium balance studies showed increased intestinal absorption ${ }^{67}$ during the acute illness, but a history of excessive vitamin $D$ intake is usually lacking, hence the hypothesis that these infants are 'vitamin D sensitive'. 5

Only three previous studies have measured the plasma metabolites of vitamin D in this syndrome. Aarskog $e t a l^{8}$ measured 25-hydroxyvitamin D and 1,25-dihydroxyvitamin $\mathrm{D}$ in one patient during the hypercalcaemic phase, and the concentration of each metabolite was normal. (Throughout our paper, unless it is specifically stated, any measurement of a metabolite of 'vitamin D' implies that the total metabolites of vitamin D2 and D3 have been estimated.) Taylor $e t a l^{9}$ gave a pharmacological dose of vitamin D2 $(1500 \mathrm{IU} / \mathrm{kg})$ to six patients with normal calcium values whose mean age was 8 years, and reported normal baseline concentration of 250 hydroxyvitamin $D$ but a greater increase in 25 hydroxyvitamin $\mathrm{D}$ concentrations in cases than age matched controls. More recently, Garabedian et al ${ }^{10}$ described raised 1,25-dihydroxyvitamin $\mathrm{D}$ concentrations that seemed to decrease over the first 2 to 4 years of life, in four patients with this syndrome. Three of these patients, however, were not mentally handicapped, had no cardiovascular abnormality, and were diagnosed purely on the presence of an elfin facies. The only infant with hypercalcaemia, mental handicap, and a cardiovascular anomaly had normal 1,25-dihydroxyvitamin $\mathrm{D}$ values.

We have previously reported a clinical study of 117 patients with this syndrome, and report here the plasma concentrations of vitamin D metabolites in a random sample of 83 of these, an age matched control group, and two further patients with the same syndrome during the hypercalcaemic phase of their illness. Specific high performance liquid chromatographic and mass fragmentographic assays were used.

\section{Patients}

All patients fulfilled the selection criteria suggested by Martin et al. ${ }^{4}$ Their sex ratio and mean age are $\stackrel{?}{\cdot}$ shown in Table 1 . They were divided into two 7 groups depending on the presence (group 1) or 
Table 1 Details of each study group. Group 1 comprised patients with, and group 2 those without, documented hypercalcaemia.

\begin{tabular}{llll}
\hline & Group 1 & Group 2 & Controls \\
\hline No & 52 & 31 & 33 \\
Age (yrs). Mean (SEM) & $11.8(1 \cdot 1)$ & $13 \cdot 0(1 \cdot 4)$ & $11 \cdot 6(1.9)$ \\
Boy:Girl & $30: 22$ & $16: 15$ & $21: 12$ \\
Sample date.* Mean (SEM) & $0.36(0 \cdot 03)$ & $0.29(0.04)$ & $0.36(0.03)$
\end{tabular}

*Blood sample date is expressed as the decimal of a year and the mean date was calculated for each group.

absence (group 2) of documented hypercalcaemia in infancy. A control group was drawn from caucasian children admitted to hospital for routine elective surgery, with no clinical suspicion of an abnormality of calcium metabolism, or from healthy members of the laboratory staff.

Two children were studied soon after diagnosis at 6 months (case 1) and 11 months (case 2) of age, before treatment of their hypercalcaemia. Both were developmentally delayed, had elfin facies, and a cardiac murmur. Case 1 had nephrocalcinosis and case 2 had echocardiographic evidence of mild supravalvular aortic stenosis. In both, calcium values became normal on treatment with a low calcium diet, and on follow up, both conform to the clinical syndrome.

\section{Methods}

Blood samples were taken at varying times throughout one year, the day of sampling is expressed as a decimal of one year and the mean was calculated for each group (Table 1). Plasma was separated immediately and stored at $-20^{\circ} \mathrm{C}$ until analysed. Metabolites of vitamin D were extracted from plasma as described by Rhodes et al ${ }^{11}$ using commercially available, prepacked microparticulate silica cartridges (Sep-Pak C18; Waters Associates, USA). Subsequent fractionation on Sep-Pak Sil cartridges gave three fractions, vitamin $\mathrm{D}, 25$-hydroxyvitamin $\mathrm{D}$, and polyhydroxylated vitamin $\mathrm{D}$. Concentrations of 25-hydroxyvitamin D2 and 25-hydroxyvitamin D3 were assayed by high performance liquid chromatography after isomerisation to isotachysterol. ${ }^{12}$ Concentrations of 24,25-dihydroxyvitamin D3 and 25,26-dihydroxyvitamin D3 were assayed by gas chromatography mass fragmentography. ${ }^{13} 14$ The 1,25-dihydroxyvitamin $\mathrm{D}$ value was estimated by receptor binding assay using the 1,25-dihydroxyvitamin $D$ receptor protein obtained from chick duodenum cytosol. ${ }^{15}$ This assay does not distinguish between 1,25-dihydroxyvitamin D2 and 1,25dihydroxyvitamin D3. Statistical comparisons were made with the Mann-Whitney $U$ test (two tailed).

\section{Results}

The mean (SEM) values of each metabolite in each of the study groups are shown in Table 2 and the values obtained for the two hypercalcaemic infants in Table 3.

There were no significant differences in the concentrations of any metabolite between groups 1 and 2 but the plasma 25-hydroxyvitamin D3 concentration in each of the patient groups was significantly less than in controls. Plasma 25,26-dihydroxyvitamin D3 was also significantly lower in both patient groups compared with controls, and there was a similar trend, just failing to reach conventional significance, for 24,25-dihydroxyvitamin D3. There was no significant difference between any of the groups in the case of 25-hydroxyvitamin D2 or 1,25dihydroxyvitamin D. Plasma values of 24,25dihydroxyvitamin D3 and 25,26-dihydroxyvitamin D3 correlated significantly $(\mathrm{P}<0.05)$ with 25 -hydroxyvitamin $\mathrm{D} 3$ values $(\mathrm{r}=0.67,0.57$ respectively).

The two hypercalcaemic patients have been considered separately; these patients were studied

Table 2 The mean (SEM) plasma concentrations of the metabolites of vitamin D2 and vitamin D3 in each study group. Samples were not always sufficient for each estimation and the number assayed in each group are shown in parenthesis below the mean (SEM) values

\begin{tabular}{|c|c|c|c|}
\hline & Group 1 & Group 2 & Group 3 \\
\hline$\underset{(\mathrm{n})}{25 \mathrm{OHD} 2}(\mathrm{ng} / \mathrm{ml})$ & $\begin{array}{l}3 \cdot 3(0 \cdot 7) \\
(46)\end{array}$ & $\begin{array}{l}2 \cdot 0(0 \cdot 3) \\
(27)\end{array}$ & $\begin{array}{l}2 \cdot 6(0 \cdot 6) \\
(27)\end{array}$ \\
\hline $\begin{array}{l}25 \text { OHD3 } \\
(\mathrm{n})\end{array}$ & $\begin{array}{l}14 \cdot 7(0 \cdot 9)^{*} \\
(52)\end{array}$ & $\begin{array}{l}14 \cdot 0(1.4)^{*} \\
(30)\end{array}$ & $\begin{array}{l}21 \cdot 0)(2 \cdot 4) \\
(30)\end{array}$ \\
\hline $\begin{array}{l}24.25 \text { OHD3 }(\mathrm{ng} / \mathrm{ml}) \\
(\mathrm{n})\end{array}$ & $\begin{array}{l}0.75(0 \cdot 10) \dagger \\
(40)\end{array}$ & $\begin{array}{l}0.84(0 \cdot 14) \\
(22)\end{array}$ & $\begin{array}{l}1 \cdot 14(0 \cdot 24) \\
(20)\end{array}$ \\
\hline $\begin{array}{l}25,26 \mathrm{OHD} 3(\mathrm{ng} / \mathrm{ml}) \\
(\mathrm{n})\end{array}$ & $\begin{array}{l}0 \cdot 19\left(0 \cdot(02)^{*}\right. \\
(31)\end{array}$ & $\begin{array}{l}0.20(0.03)^{*} \\
(19)\end{array}$ & $\begin{array}{l}0 \cdot 35(0 \cdot 07) \\
(10)\end{array}$ \\
\hline $\begin{array}{l}1.25 \mathrm{OHD} \\
(\mathrm{n})\end{array}$ & $\begin{array}{l}51 \cdot 7(7 \cdot 1) \\
(38)\end{array}$ & $\begin{array}{l}53 \cdot 7(17 \cdot 7) \\
(20)\end{array}$ & $\begin{array}{l}58 \cdot 5(12 \cdot 2) \\
(17)\end{array}$ \\
\hline
\end{tabular}

${ }^{*}$ Groups 1 and $2 v$ controls $\mathrm{P}<0 \cdot(05$

tGroups 1 and $2 v$ controls $P=() \cdot 1$.

$\mathrm{OHD}=$ dihydroxyvitamin $\mathrm{D}$.

Table 3 Biochemical data on the two infants with hypercalcaemia and idiopathic infantile hypercalcaemia. The reference range for each vitamin $D$ metabolite is also given and was derived from the control group (Table 2) whose mean age was 11.6 years, ranging from 1-28 years

\begin{tabular}{llll}
\hline & Case 1 & Case 2 & $\begin{array}{l}\text { Controls } \\
\text { Mean }(S D)\end{array}$ \\
\hline Age (mths) & 6 & 11 & - \\
Plasma calcium $(\mathrm{mmol} / \mathrm{l})$ & $3 \cdot 4$ & $3 \cdot 2$ & - \\
25 OHD2 $(\mathrm{ng} / \mathrm{ml})$ & $33 \cdot 1$ & $8 \cdot 0$ & $2 \cdot 6(2 \cdot 9)$ \\
$25 \mathrm{OHD3}(\mathrm{ng} / \mathrm{ml})$ & $15 \cdot 3$ & $26 \cdot 1$ & $21 \cdot 0(13 \cdot 1)$ \\
$24.25 O H D 3(\mathrm{ng} / \mathrm{ml})$ & $1 \cdot 06$ & $3 \cdot 42$ & $1 \cdot 1(1 \cdot 1)$ \\
$1.25 O H D(\mathrm{pg} / \mathrm{ml})$ & $28 \cdot 6$ & $43 \cdot 5$ & $58 \cdot 5(49 \cdot 1)$ \\
\hline
\end{tabular}


independently and very similar results were obtained (McGraw M, Mawer E B, personal communication).

\section{Discussion}

All but two patients in this study had normal calcium values, but as recurrence of hypercalcaemia has been reported in at least one case, ${ }^{4}$ it was theoretically possible that changes in the vitamin $\mathrm{D}$ metabolites might be detected in the 'burnt out phase' of the syndrome. Significantly lower concentrations of 25-hydroxyvitamin D3 have been found in patients with this syndrome, but this is unlikely to be of aetiological importance. It seems more probable that this is a secondary phenomenon related to their mental handicap since these subjects may have a less active, more sedentary, indoor lifestyle with less exposure to sunlight.

Although no mentally handicapped control group was available to confirm this hypothesis, Taylor $e t$ $a l^{9}$ studied six patients with this syndrome. Their data showed the same trend, although their assay measured only total 25 -hydroxyvitamin $\mathrm{D}$, and did not distinguish between the individual 25-hydroxy derivatives of vitamin D2 and D3. Moreover, these lower substrate values may well explain their findings of increased 25-hydroxyvitamin $\mathrm{D}$ synthesis after pharmacological challenge with vitamin D2, since there is evidence for the induction of 25hydroxylase activity in states of relative substrate deficiency. ${ }^{16}$

The two hypercalcaemic infants we studied also failed to show any abnormality in the metabolism of vitamin $\mathrm{D}$. The concentrations of the active vitamin D hormone responsible for calcium absorption from the gut, 1,25-dihydroxyvitamin $\mathrm{D}$, were within the reference range for our control group, whose mean age was 11.6 years, and indeed tended to be at the lower end of this range. Lund et al ${ }^{17}$ have shown higher concentrations of 1,25-dihydroxyvitamin $\mathrm{D}$ in the first two years of life than in later childhood, and a significant positive correlation with growth velocity. Therefore the low 1,25-dihydroxyvitamin D values found in these two patients suggests that there is either appropriate suppression of $1 \alpha$,hydroxylase activity in the presence of hypercalcaemia or perhaps that their growth velocity is reduced secondary to their hypercalcaemia.

The 25-hydroxyvitamin D2 values seem, at first sight, to be raised, since the ratio of 25-hydroxyvitamin D3:25-hydroxyvitamin D2 for adults is in the order of $9: 1$. For infants fed 'fortified' milk feeds, however, 25-hydroxyvitamin D2 values are certainly higher, and have been shown to rise during the first month of life. ${ }^{18}$ Certainly they are not within the range associated with vitamin D toxicity.

Although confirmation of these findings in other $\stackrel{9}{\rightarrow}$ infants with idiopathic infantile hypercalcaemia is required, this is the first comprehensive study of $\frac{\overline{ }}{\bar{*}}$ vitamin D metabolites in a large group of patients $\frac{\bar{s}}{\vec{D}}$ with well documented idiopathic infantile hypercal- $\stackrel{\oplus}{\circledR}$ caemia. No specific abnormality of vitamin $D \cong$ metabolism in either the hypercalcaemic or normocalcaemic phases of this syndrome has been identi-. fied, and we have also failed to detect any abnor- $\overrightarrow{\vec{\omega}}$ mality of the kinetics of 25-hydroxyvitamin D3 $\stackrel{2}{\circ}$ turnover in adolescents with this syndrome who are in the normocalcaemic phase.

Thus, although abnormalities in the metabolism of both 25-hydroxyvitamin $\mathrm{D}^{9}$ and 1,25-dihydroxy- $\overrightarrow{\mathrm{N}}$ vitamin $D^{10}$ have been suggested as the cause of $\vec{A}$ hypercalcaemia in this syndrome, we have been $\overrightarrow{\vec{A}}$ unable to show any abnormality of vitamin $D_{\circ}$ metabolism. This is in agreement with the findings of Aarskog et al. ${ }^{8}$ We suggest that more patients $\overrightarrow{0}$ with clear evidence of idiopathic infantile hypercal- $\mathbb{D}$ caemia and the associated dysmorphic syndrome, $\mathbb{\Phi}$ which is perhaps best described by its eponym The $\frac{7}{0}$ Williams-Beuren syndrome, require to be studied $\stackrel{\Phi}{-}$ during and after the hypercalcaemic phase, using $\vec{\varphi}$ specific high performance chromatographic and on mass fragmentographic assays to estimate the ind:vidual metabolites of vitamin D2 and vitamin D Further study is also needed to examine the relation between hypercalcaemia and mental handicap and the characteristic cardiovascular anomalies.

This study was supported by Action Research for the Crippled $\overrightarrow{\bar{O}}$ Child and The Infantile Hypercalcaemia Foundation. HLJM and 3 DHT were in receipt of grants from The Special Trustees of The London Hospital, The Medical Research Council, and The Wellcome Trust. The research was made possible by Sir George and Lady Cynthia Cooper and other members of The Infantile Hypercalcaemia Foundation.

\section{References}

' Fanconi G, Giardet P, Schlesinger B, Butler N, Black JS. ̊ Chronische hypercalcamie kombiniert mit osteosklerose, hyperazotamie, minderwuschs und kogenital missbildungen. Helv $\mathrm{O}$ Paediatr Acta 1952;7:314-34.

2 Williams JCP, Barratt-Boyes BG, Lowe J. Supravalvular aortic stenosis. Circulation 1961;24:1311-8.

${ }^{3}$ Garcia RE, Friedman WE, Kabak MM, Rowe RD. Idiopathic hypercalcaemia and supravalvular aortic stenosis. Documenta- $\mathcal{N}$ tion of a new syndrome. $N$ Engl J Med 1964;271:117-20.

4 Martin NDT, Snodgrass GJAI, Cohen RD. Idiopathic infantile $N$ hypercalcaemia-a continuing enigma. Arch Dis Child N్ 1984;59:605-13.

5 Lightwood R. Signification des troubles du metabolisme dans la genese du marasme. Arch Fr Pediatr 1953;10:190-3.

6 Morgan HG, Mitchell RG, Stowers JM, Thompson J. Metabolic studies in two infants with idiopathic hypercalcaemia. Lancet $\stackrel{\mathcal{Q}}{\longrightarrow}$ 1956;: $: 925-31$.

7 Stapleton T, Evans IWJ. Idiopathic hypercalcaemia of infancy. Helv Paediatr Acta 1955;10:149-55. 
${ }^{8}$ Aarskog D, Aksnes L, Markestadt T. Vitamin D metabolism in idiopathic infantile hypercalcaemia. Am J Dis Child 1981; 135:1021-4

" Taylor AB, Stern PH, Bell NH. Abnormal regulation of circulating 25-hydroxyvitamin $\mathrm{D}$ in the Williams syndrome. $N$ Engl J Med 1982;306:972-5.

10 Garabedian M, Jacqz E, Guillozo $\mathrm{H}$, et al. Elevated plasma 1,25-dihydroxyvitamin $\mathrm{D}$ concentrations in infants with hypercalcaemia and an elfin facies. $N$ Engl J Med 1985;312:948-52.

$"$ Rhodes CJ, Claridge PA, Trafford DJH, Makin HLJ. An evaluation of the use of Sep-Pak C18 cartridges for the extraction of vitamin D3 and some of its metabolites from plasma and urine. J Steroid Biochem 1983;19:1349-54.

12 Turnbull H, Trafford DJH, Makin HLJ. A rapid and simple method for the measurement of plasma 25-hydroxyvitamin D2 and 25-hydroxyvitamin D3 using Sep-Pak C18 cartridges and a single high-performance liquid chromatographic step. Clin Chim Acta 1982:120:65-76.

13 Coldwell RD, Trafford DJH, Makin HLJ, Varley MJ, Kirk DN. Specific estimation of 24,25-dihydroxyvitamin D in plasma by gas chromatography, mass-spectrometry. Clin Chem 1984;30: 1193-8.
14 Coldwell RD, Trafford DJH, Makin HLJ, Varley MJ, Kirk DN. A specific mass-fragmentographic assay for 25,26-dihydroxyvitamin $D$ in human plasma using a deuterated internal standard. J Chromatogr 1985;338:289-302.

15 France MW, Lalor B. A competitive protein binding assay for 1,25-dihydroxyvitamin $\mathrm{D}$ in blood. Irish J Med Sci 1981; 150:310-3.

${ }^{16}$ Mawer EB, Lumb GA, Schaefer K, Stanbury SW. The metabolism of isotopically labelled vitamin D3 in man: the influence of the state of vitamin D nutrition. Clin Sci 1971;40:39-53.

17 Lund B, Clausen N, Lund B, Andersen E, Sorensen OH. Agedependent variations in serum 1,25-dihydroxyvitamin $D$ in childhood. Acta Endocrinol 1980;94:426-9.

${ }^{18}$ Kuroda E, Okano T, Mizuno N, et al. Plasma levels of 25 hydroxyvitamin D2 and 25-hydroxyvitamin D3 in maternal, cord and neonatal blood. J Nutr Sci Vitaminol 1981;27:55-65.

Correspondence to Dr N D T Martin, Paediatric Cardiology Department, Guy's Hospital, St Thomas's Street, London SE1 9RT.

Received 9 July 1985 